\title{
EFFECT OF LAND-USE ON SOIL PROPERTIES IN NE PART OF ROMANIA
}

\author{
DOI: $\quad$ https://doi.org/10.18509/AGB.2020.08 \\ UDC: $631.41(498)$
}

\author{
Alexandra Petronela Stoleriu ${ }^{1,2}$, Iuliana Gabriela Breaban ${ }^{1,2}$, Constantin Rusu $^{3}$
}

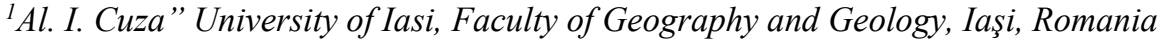 \\ ${ }^{2}$ Integrated Center of Environmental Science Studies in the North Eastern Region - CERNESIM, Iasi, Romania \\ ${ }^{3}$ Romanian Academy, Iasi Branch, Iasi, Romania
}

corresponding author:

submitted: 09.02.2020

accepted: 04.04.2020

published: 15.06 .2020

\begin{abstract}
In order to achieve successful agriculture, it is necessary for sustainable use of the soil resources, because soils can lose their quality. Therefore, for sustainable agricultural practice is required basic knowledge regarding the rational use of the land. A success in soil management to maintain the quality depends on the understanding of how the soil responds to agricultural practices over time. Recent interest in evaluating the quality of our soil resource has therefore been simulated by increasing awareness that soil is a critically important component of the earth's biosphere. Soil properties can be affected by land-use types, through addition and removal of the nutrient element. Therefore, an assessment of the soil fertility status is required periodically, to adopt appropriate land management practices; to increase soil productivity, resulting in high crop production.

The aim of this study was to analyse the effect of land-use on physicochemical soil properties for different types of culture. Samples were collected according to horizon differentiation, and also at predetermined depths of 0-15 and 15$30 \mathrm{~cm}$ in all land use types, giving a total of 48 samples, humus, total N (TN); available P (AP); available K (AK); $\mathrm{pH}$. Soil samples were collected from different uses of land, namely arable land, pastures, vineyards, hygrophilous vegetation, and unproductive land. Valea Oii is located in the north-eastern part of Romania and occupies a central-western position in the Bahlui watershed, having a catchment area of $97 \mathrm{~km} 2$. Soil chemical properties are the most important among the factors that determine the nutrient supplying power of the soil to the plants. The chemical reactions that occur in the soil affect soil development and fertility. To increase soil organic matter and other nutrients in the soil of cultivated land, it is proposed to implement on a large scale some elementary measures for soil and water conservation, which would favor the optimum use of agricultural land (land management through compost, cover crops, manures, minimum tillage, crop rotation).
\end{abstract}

Keywords: land use, soil properties, horizons, agriculture, NE part of Romania

\section{INTRODUCTION}

The soil is a natural body dependent on the parental material and the pedogenetic processes to which it was exposed. With regard to soil properties (physical, chemical and biological), they have dynamic variability, both vertically and horizontally. In order to know and understand the effects of land use types and their management it is necessary to monitor the variation of soil properties. Over time, studies on the variability of soil properties have analyzed several factors such as: land slope, crop types, but also land use [1]. Soil properties are very important characteristics, especially when used for agronomic purposes. The land use in an area must take into account the compatibility between physical - chemical, bioclimatic characteristics and crop types [2]. In practice, especially in the case of individual farmers or small farms, the use of land is not alwayscorrelated with the soil type, the decisions depending on the level of education and experience of the land owners. However, the efficiency with which land use systems can be optimized will be based on soil properties that must correspond to the requirements of the crop type.

The type of land use, soil management practices influence soil nutrients and soil processes, such as erosion, oxidation, mineralization and runoff $[3,4]$, the transport and redistribution circuits of nutrients being modified. In fallow lands, the type of vegetative cover represents a factor that influences the organic matter content of the soil, which leads to the compulsory determination of soil 
characteristics [3]. The data regarding the physical and chemical properties of the soil are of particular importance in the planning and management of spatial variations of the soil, saving both time and financial resources, directly influencing the proper management of soil and crops, as well as the efficiency of soil research [5]. Inadequate soil management can lead to rapid deterioration of important land areas, often becoming a major threat

\section{MATERIAL AND METHODS Study area}

The Valea Oii catchment is located in the northeastern part of Romania and occupies a centralwestern position within the Bahlui catchment (Figure 1), with an area of $97 \mathrm{~km}^{2}$. Although it has a small area, the catchment stretches over two wellindividualized areas within the Moldovan Plateau: the Moldavian Plain $(84.60 \%$ of the total area of the catchment) and the Suceava Plateau (15.40\%); besides the two zones, there are other subunits: the coast of Dealului Mare-Hârlău (Suceava Plain). [6] The substrate is formed by quaternary deposits with cryptomacra, with variable petrographic composition with sands, loamy and heavy clay and clays.

Five soil classes from the study area (Cernisols, Hydrisols, Protisols, Anthriosols and Luvisols) were divided into nine soil types (Figure 2). According to the study conducted by OJSPA Iași [7], the Cernisols class has the largest expansion in the study area (5419.43 ha), represented by chernozems with an area of 4643.78 ha $(47.88 \%)$, followed by phaeozems occupying an area of 675.1 ha $(6.96 \%), 14.40 \%$ being occupied by other types of soils from the other classes. A quite significant area of land $(18.19 \%)$ is covered by soil complexes where various soil associations are found.

\section{Methodology}

The soil map was based on the pedological studies from OSJPA [7] Iasi, and the land use map was to rural livelihoods in many developing and developed countries. Rarely, the consequences of changes in the land use on the soil are difficult to highlight, which leads to the delay of the initiation of ameliorative measures by the administrators of the respective lands.

The aim of this study was to analyse the effect of land-use on physicochemical soil properties for different types of culture.].

made based on 2012 orthophotoplan [8] and the CLC from 2018 [9].

From the main categories of land use identified in the area, data from 48 georeferenced soil profiles which include different soil parameters $(n=10)$ were extracted from the Local Soil Survey database [7] including arable land (39), grassland (2), orchards (1), vines (1), non-productive lands (4) and hydrophilic vegetation (1). For the present study database were taking into account: $\mathrm{pH}$, humus, total $\mathrm{N}, \mathrm{P}$ assimilable, $\mathrm{K}$ assimilable and the texture for 2018 from the first $30 \mathrm{~cm}$.

In order to reveal statistically significant differences between the physical and chemical properties of the soil and the land uses, the variance was analysed (parametric one-way ANOVA). The dependence between land use and the soil physicalchemistry properties type were tested using the Pearson chi-square test contingency table and the correlation between soil properties by Spearman's rank order correlation, by principal component analysis (PCA) and hierarchical cluster analysis (HCA) for quantitative evaluation of multivariate relationships between data. PCA and HCA have been used to distinguish different groups of physical-chemical properties as traces of natural or anthropic sources. The analysis was performed using XLSTAT trial version (https://www.xlstat.com/en/) [10]. The tests were performed at a $95 \%$ confidence interval. [11] 


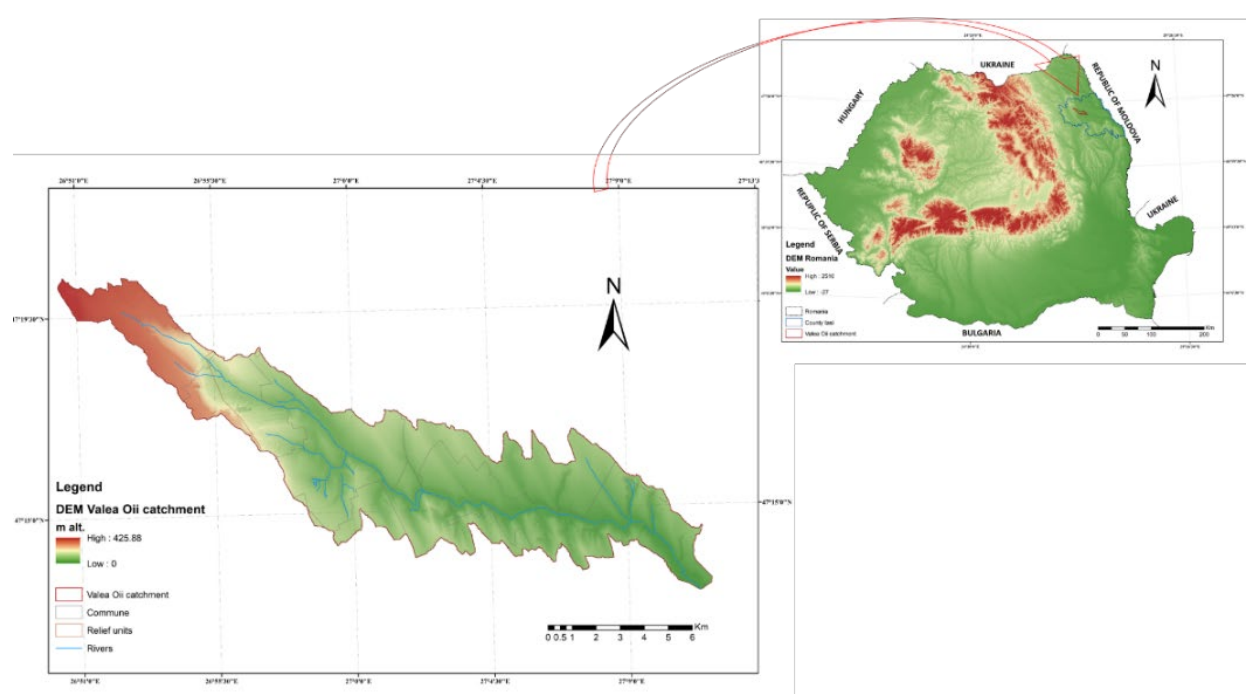

Figure 1. Valea Oii catchment located in north-eastern part of Romania

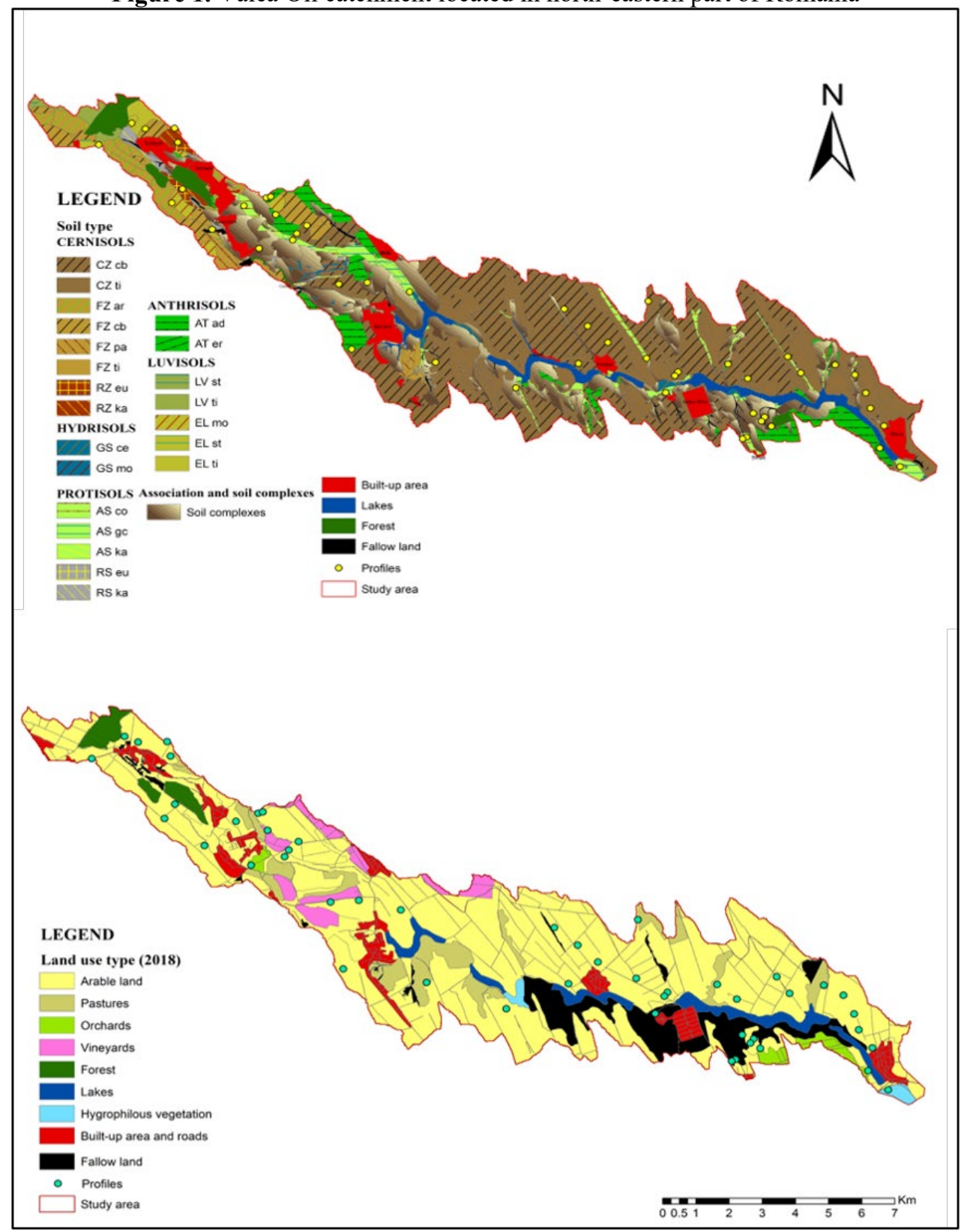

Figure 2. Soil and land use map of the study area 


\section{RESULTS}

The land use and management practices directly influence all types of soil properties. The increased need to provide food resources for the population has over time led to the transformation of forestcovered land into arable land, leading to degradation of soil cover and modification of nutrient cycles and flows, becoming a worldwide concern. Intensive farming techniques have generated consequences that are difficult to predict on soils and groundwater, so that the pattern left could be detected even after the activity is stopped. In this sense, on arable land, the amount of soil organic matter is generally lower, compared to the soils of forests or natural grasslands, with the crops benefiting from the initial reserve, the input / output ratio being favorable to consumption. Disruption of the degree of cover with vegetation of the lands, leads to higher soil erosion rates and consequently losses of nutrients and organic matter with consequences in lowering the buffering capacity and that of cation exchange, soil productivity, reducing biodiversity. Soil sustainability requires regular assessment of soil fertility status and quality, as it provides quality knowledge of the factors that impose restrictions on increasing crop production and soil productivity in different types of land use and for adopting appropriate management practices. Of the entire surface of the basin ( $9700 \mathrm{ha}$ ), about 3/5 belong to agricultural lands and only $2 / 5$ to non-agricultural ones (Table 1). This fact indicates an intense transformation of the initial vegetal cover (from forests and pastures) into arable land surfaces.

Table 2. Evolution of land use categories between 1950-2018 in the Valea Oii catchment

\begin{tabular}{|c|c|c|c|c|c|c|c|c|c|c|c|c|}
\hline [ha] & & \multicolumn{5}{|c|}{ Arable } & \multicolumn{6}{|c|}{ Built-up Fallow Hygrophilous } \\
\hline 1950 & all & 4351 山 & 1666.4 & 969.4 & 230.54 & 4 正 & will & 세 332.4 메 & 230.13 페 & 402.6 I & 1116.98 & Topographic plans \\
\hline 2005 & & 6395 ill & 1157.7 & 126.06 & 200.77 & 7 넹 & 武 290.5 & 페 182.9 베 & 383.73 & 651 네 & 42.6 & Ortophotoplan \\
\hline 2012 & il & 6102 떼 & 862.71 & 106.04 & 106.79 & 9 - 356.5 & 5 네 332.1 & 네 231.7 네 & 386.6 & 1152 네 & 65.17 & \\
\hline 2018 & 4 & 6542 जी & 702.48 & 132.5 & 314.57 & 7 政 200.6 & $6-1371$. & 페 154.2 네 & 428.9 - & 782.1 跑 & 72.01 & $C L C$ \\
\hline
\end{tabular}

The arable lands were more frequent in the flat areas with gentle slopes, and the non-productive lands were more frequent on the north-facing slopes and with low isolation slopes. There was no significant dependence between soil type and land use. (Table 2)

Table 2. Mean values and standard deviations (SD) of measured soil properties

a) and the correlations between them; b) in on land use types in the studied region;

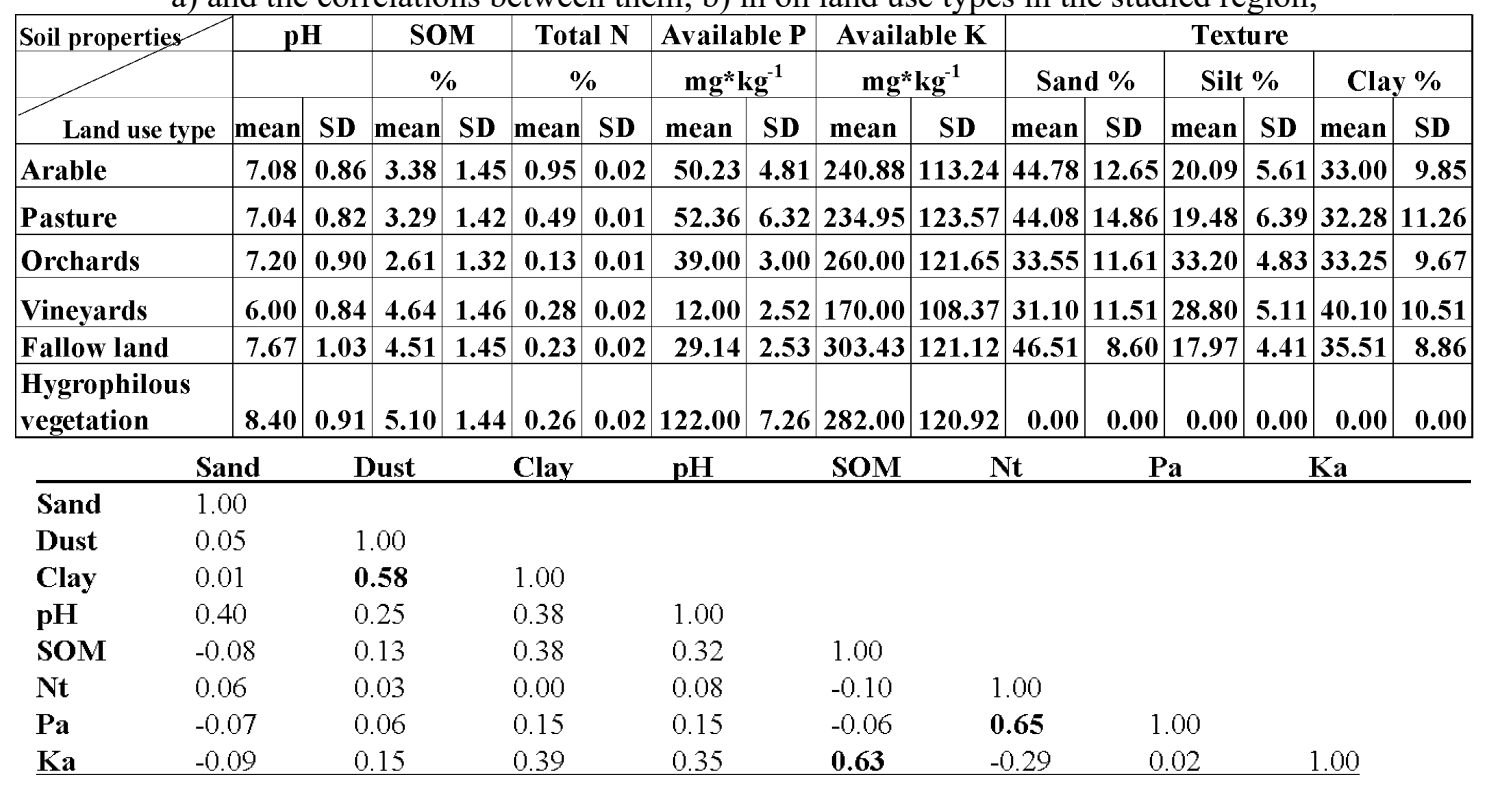




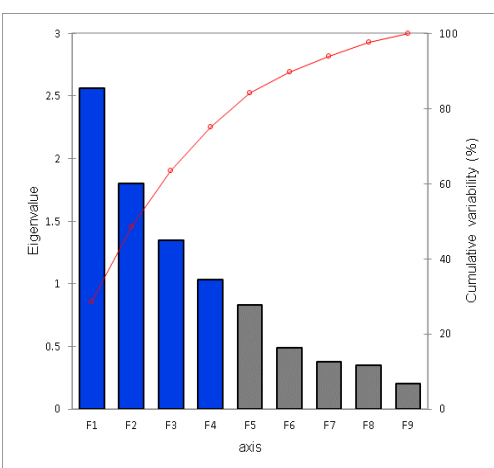

a)
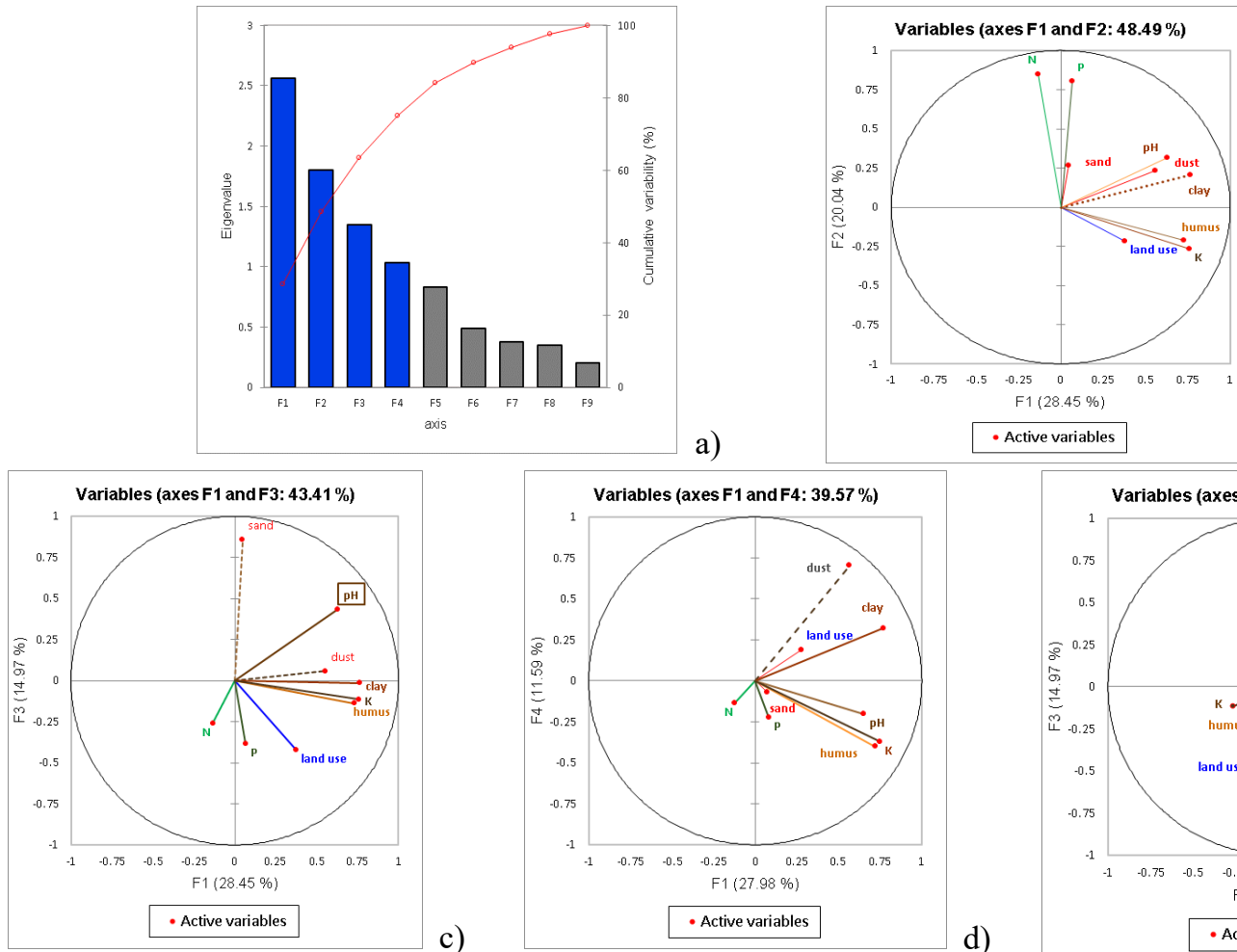

d)

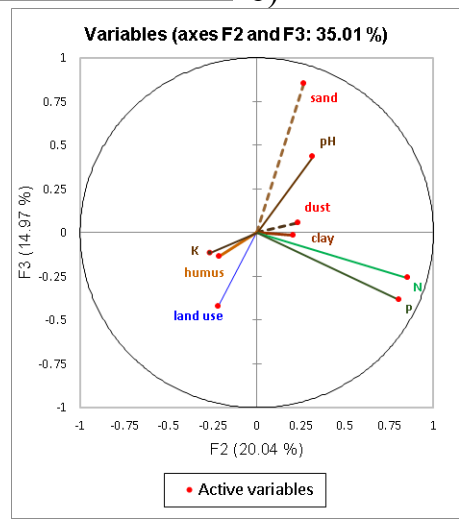

e)

Figure 3. PCA results for soil chemical properties of topsoil a) Eigenvalue diagram;

b) Correlation circle on F1-F2 axes; c) F1-F3 axes; d) F1-F4 axes; e) F2-F3 axes

Topsoil's under different land uses indicate a rather low variability of the physical - chemical properties measured over the entire studied area (table 2). It is characterized by the positive loadings of most of the variables. Clay, dust $\mathrm{pH}, \mathrm{Nt}$, and $\mathrm{Pa}$ have higher positive loadings, showing the similar patterns among all sampling points. On the other hand, only sand with SOM- Pa - Ka and SOM with $\mathrm{Nt}-\mathrm{Pa}$ show negative loadings. Those results correspond to the strong linear correlation of $\mathrm{Pa}-\mathrm{Nt}$, SOM - Ka and dust-clay. Analysis of the variance and its nonparametric equivalent revealed that several measured chemical properties show significant differences in average or average values between land uses. PCA has been extensively used by various researchers to identify key soil quality indicators, being used to examine the correlation between each soil variable with the locally derived components and shows geographic variations in multiple soil characteristics across space. The principal components (PC) are generated from PCA as linear combinations of the original data. The PC1 explained about $29 \%$, PC2 accounts additional for $20.2 \%$ of total variance while PC3 accounts $14.97 \%$ and PC4 11. 59\% (Figure 3). From screen plot graph of eigenvalues of the PCA-soil model (Figure 4) it can be seen that the first two PCs are enough to explain almost $50 \%$ of the pattern variation. Land use, texture, $\mathrm{pH}, \mathrm{SOM}$ and nutrients were major contributors to $\mathrm{PC} 1$ while the $\mathrm{Nt}, \mathrm{Pa}$ concentration was the major contributors to $\mathrm{PC} 2$, texture and $\mathrm{pH}$ being secondary contributors putting into the evidence the presence of the nitrogen consuming crops as well as the absence of the crop rotation. PC3 describes main high positive eigenvectors of sand and $\mathrm{pH}$ corresponding to the sandy soils while PC4 identify dust and clay as main eigenvectors characteristic to the loamy clay soil texture. 
Alexandra Petronela Stoleriu, Iuliana Gabriela Breaban, Constatin Rusu.

Effect of land use on soil properties in NE part og Romania.

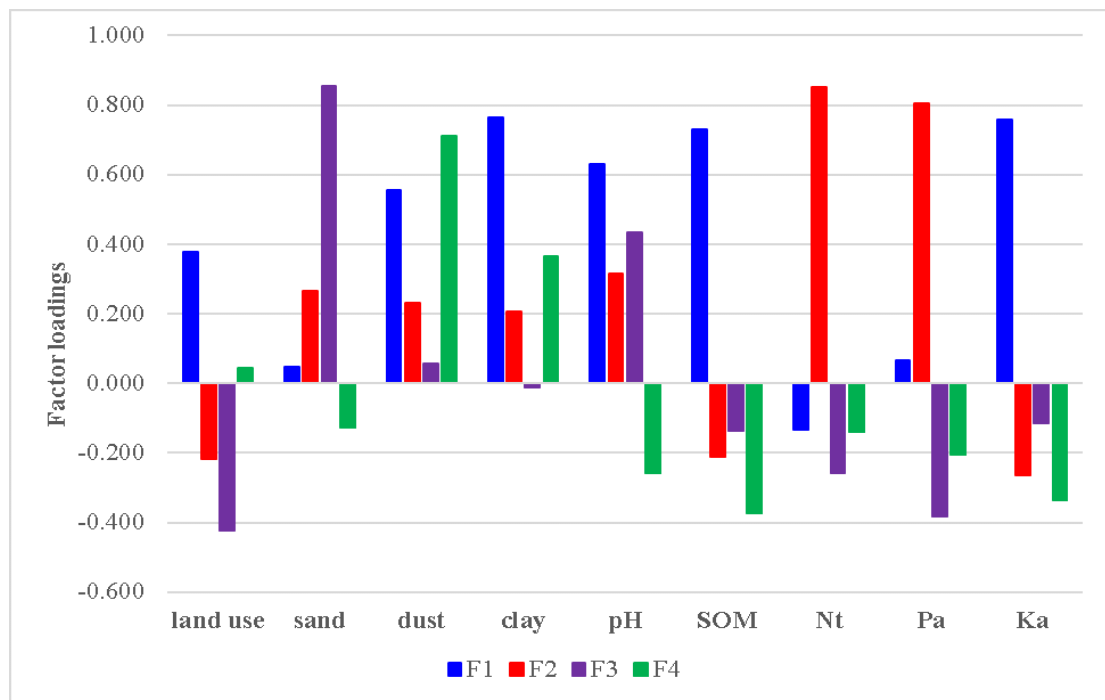

Figure 4. PC loadings of soils data from the the study area
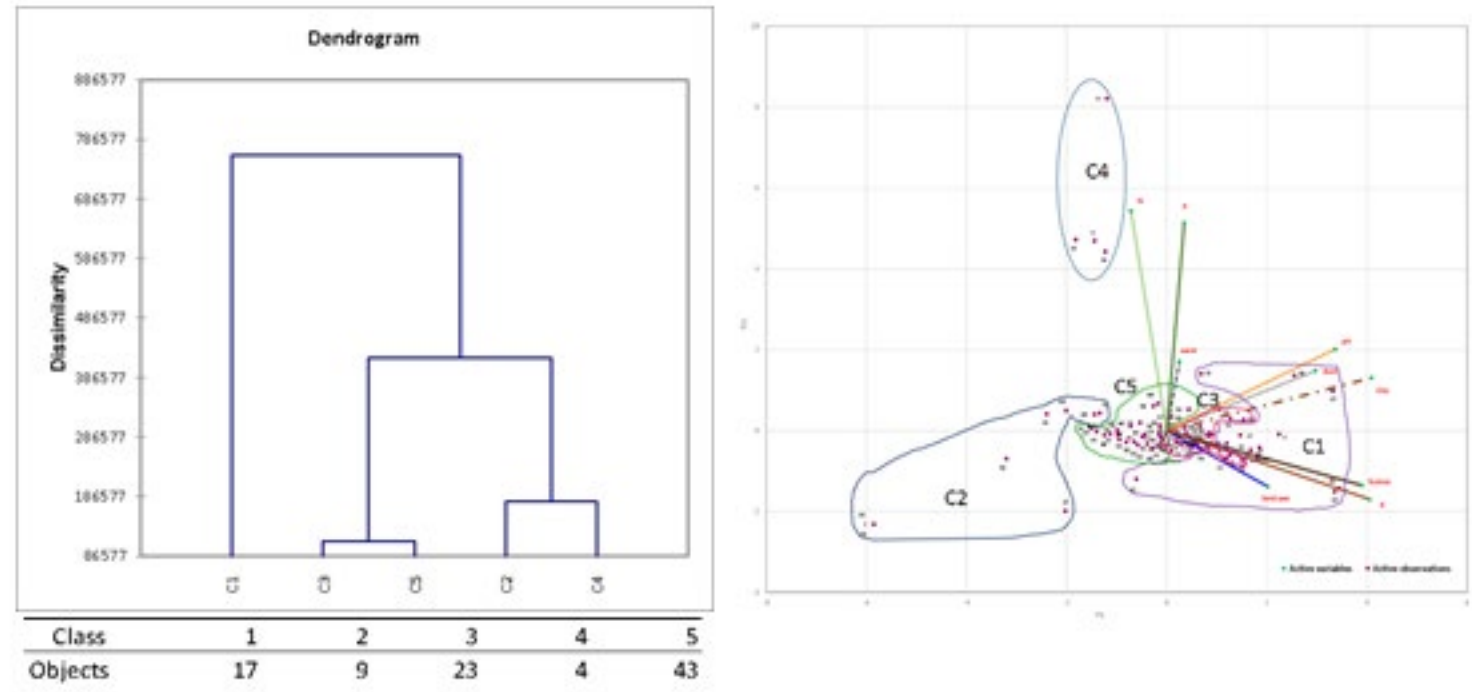

Figure 5. Cluster analysis by both Ward linkage method and Euclidean distance.
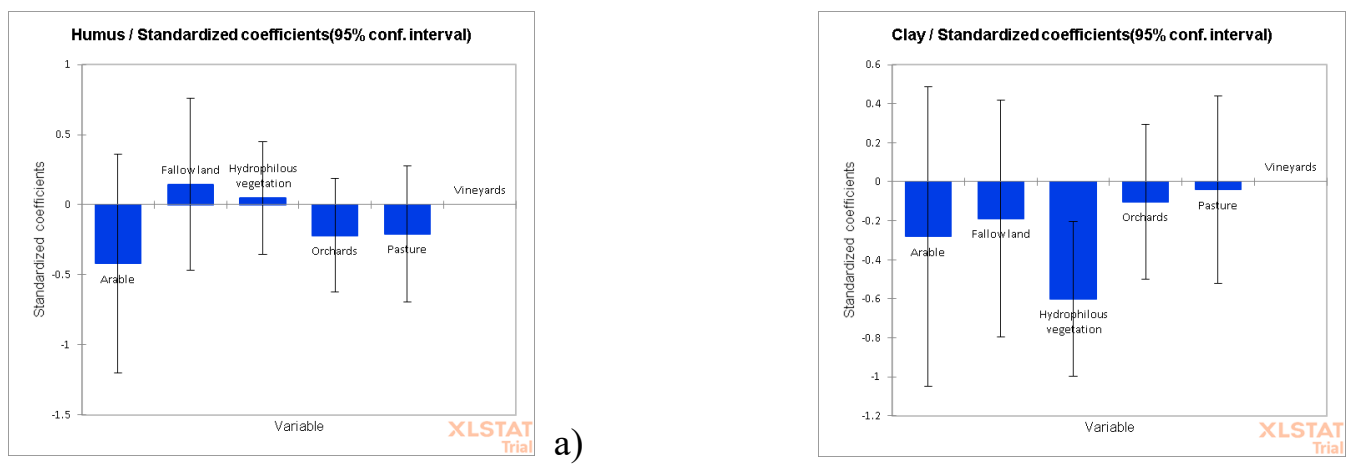

b) 


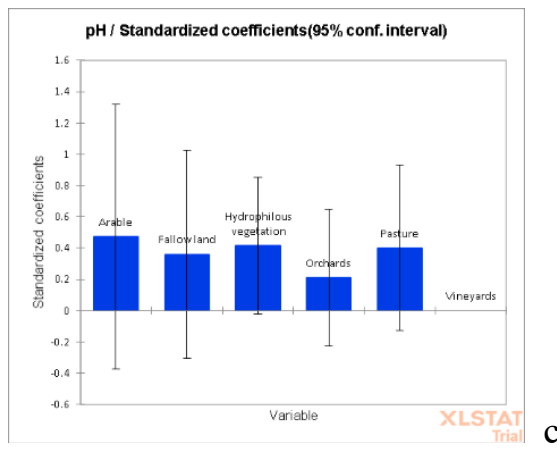

c)

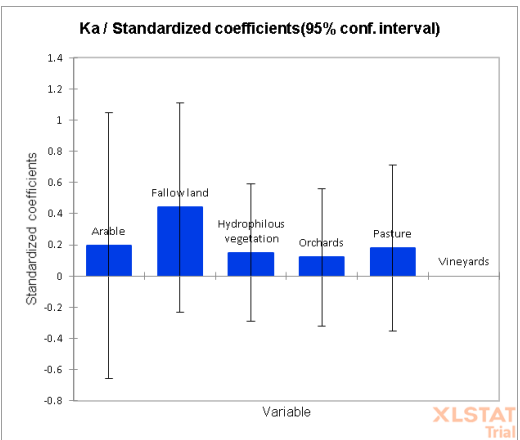

e)

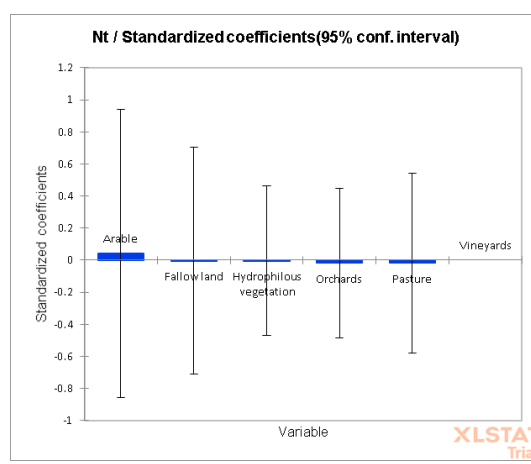

d)

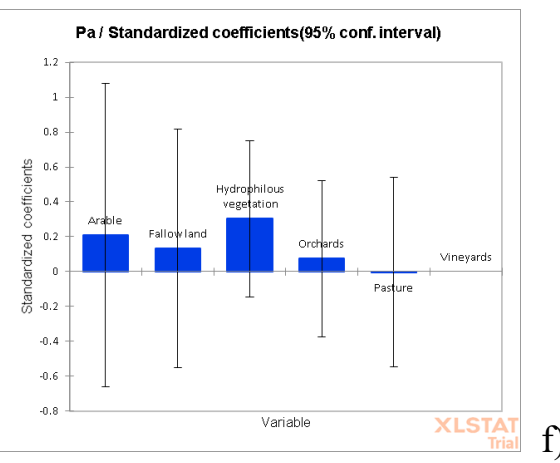

f)

Figure 6. Results of the ANOVA tests: a) Humus, b) Clay, c) pH, d) Nt, e) $\mathrm{Ka}, \mathrm{f}$ ) $\mathrm{Pa}$

The ANOVA results (Figure 6) showed that land use types significantly influenced the chemical properties of the soils in the Oii Valley catchment over the basin $(\mathrm{p}<0.05)$. Thus SOM, clay and partially $\mathrm{Nt}$ vary significantly between different types of land use, indicating a degradation of soil

\section{CONCLUSIONS}

The study was conducted to explore the spatial variability of the different soil variables (for 0$30 \mathrm{~cm})$ throughout the Valea Oii catchment. PCA and HCA were used to characterize the spatial variability of the set of 10 different soil variables. The PCA was used to describe the data set and represents an adequate statistical approach to establish the relative importance of the individual variables characteristic of soils subjected to intensive use.

The observed relationships from the PCA analysis suggest that there is an intricate connection between the various soil parameters across the entire study area which can be difficult to physically observe.

The major difference is between the land that was permanently and the agricultural one indicating that the contribution of organic fertilizers or residues quality. These results indicate that soil quality could be improved by transforming cultivated land into vegetation and that restoration of vegetation would be beneficial for SOM, $\mathrm{Nt}$ and $\mathrm{Pa}$ surface accumulation..

from the previous crops from the traditional farming system of the small farmers is insufficient, the cultivated land being exhausted by nutrients. This effect is intensified by the loss of organic matter retained in both agricultural and horticultural crops, pastures and silt caused by erosion of the soil surface. Among the soil properties affected by low organic matter content can be identified cation exchange capacity, nutrient availability and soil buffering capacity.

\section{AKNOWLEDGMENTS}

This work was financial supported by the Doctoral School of Geosciences, Department of Geography from the "Alexandru Ioan Cuza" University of Iasi,

and the infrastructure was provided through the POSCCE-O 2.2.1, SMIS-CSNR 13984-901, No. 257/28.09.2010 Project, CERNESIM.

\section{REFERENCES}

[1] Langley- Turnbaugh S. J., Keirstead D. R., Soil properties and land use history: a case study in New Hampshire, Northeastern Naturalist, 12, no. 4, pp 391-402, 2005

[2] Verheye, W. H., Principles of land appraisal and land use planning within the European community, Soil Use and Manage, 2, pp 120-124, 2005 
[3] Celik I., Land use effects on organic matter and physical properties of soil in a southern Mediterranean highland of Turkey, Soil Tillage Research, 83, pp 270-277, 2005

[4] Liu X. L., He Y. Q., Zhang H. L., Shroder J. K., Li C. L., Zhou J., Zhang Z. Y., Impact of land use and soil fertility on distributions of soil aggregate fractions and some nutrients, China, Pedosphere, 20, no. 5, pp 666-673, 2010

[5] Wasiullah A.U., Bhatti A. U., Khan F., Akmal M., Spatial variability and geostatistics application for mapping of soil properties and nutrients in semi-arid district Kohat of Khyber Pakhtunkhwa, Pakistan, Pakistan Soil \& Environment, 29, no. 2, pp 159-166. 2010,

[6] Nicu I. C., Hydrogeomorphic Risk Analysis Affecting Chalcolithic Archaeological Sites from Valea Oii Watershed, Northeastern Romania, pp 35-38, 2016.

[7] Pedological studies, County Office of Pedological and Agrochemical Studies Iași.

[8] Ortophotoplan 2012 - Geoportal of the National Agency for Cadastre and Real Estate Advertising (https://geoportal.ancpi.ro/), 2012

[9] CLC 2018 Tehnical Guidelines, European Environment Agency, 2017

[10] Addinsoft, XLSTAT software. Available online at: https:/www.xlstat.com/en/

[11] Pîrnău R. G., Patriche C. V., Roşca B., Vasiliniuc I., Vornicu N., Stan S., Soil spatial patterns analysis at the ancient city of Ibida (Dobrogea, SE Romania), via portable X-ray fluorescence spectrometry and multivariate statistical methods, Catena, 189, pp 1-12, 2020 